\title{
A FORMAÇÃO DE PROFESSORES DE CIÊNCIAS PARA UMA PRÁTICA PEDAGÓGICA INCLUSIVA
}

\author{
LA FORMACIÓN DE PROFESORES DE CIENCIA PARA UNA PRACTICA \\ PEDAGOGICA INCLUSIVA
}

TRAINING SCIENCE TEACHERS TO AN INCLUSIVE PEDAGOGICAL PRACTICE

\author{
Paloma Alinne A. RODRIGUES ${ }^{1}$
}

RESUMO: No que tange à Educação Especial na perspectiva da Educação Inclusiva, observa-se a necessidade de potencializar o currículo dos cursos de licenciatura, em especial os relacionados ao Ensino de Ciências, com disciplinas e atividades que favoreçam os conhecimentos relativos ao desenvolvimento de estratégias pedagógicas inclusivas. Além disso, considera-se relevante que as disciplinas que contemplam os aspectos inclusivos estejam alicerçadas na racionalidade prática, para possibilitar ao futuro professor subsídios para atuar com os estudantes com deficiência, síndrome e/ou transtornos. Desse modo, este trabalho tem o objetivo de apresentar resultados de uma pesquisa realizada com um grupo de licenciandos dos cursos de Física, Química, Biologia e Matemática da Universidade Federal de Itajubá (UNIFEI) no que tange aos conhecimentos teóricos e, em especial, práticos, construídos durante o período de formação para atuar com esses estudantes no contexto regular de ensino.

PALAVRAS-CHAVE: Inclusão. Ensino de ciências. Formação de professores.

RESUMEN: En lo que se refiere a la Educación Especial en la perspectiva de la Educación Inclusiva, se observa la necesidad de potenciar el currículo de los cursos de licenciatura, en especial los relacionados a la Enseñanza de Ciencias, con disciplinas y actividades que favorezcan los conocimientos relativos al desarrollo de estrategias pedagógicas inclusivas. Además, se considera relevante que, las disciplinas que contemplan los aspectos inclusivos, estén basadas en la racionalidad práctica, para posibilitar al futuro profesor subsidios para actuar con los estudiantes con discapacidad, sindrome y/o trastornos. De este modo, este trabajo tiene el objetivo de presentar resultados de una investigación realizada con un grupo de alumnos de enseñanzas de los cursos de Física, Química, Biología y Matemática de la Universidad Federal de Itajubá (UNIFEI) en lo que se refiere a los conocimientos teóricos y, en especial, prácticos construidos durante el período de formación para actuar con esos estudiantes en el contexto regular de enseñanza.

PALABRAS CLAVE: Inclusión. Enseñanza de ciencias. Formación de profesores.

${ }^{1}$ Universidade Federal de Itajubá (UNIFEI), MG - BRASIL. Professora do Instituto de Física e Química (IFQ) e coordenadora do grupo de pesquisa "Núcleo de Estudos em Formação Docente, Tecnologias e Inclusão (NEFTI)”. ORCID: <https://orcid.org/0000-0001-9005-5627>. E-mail: palomaraap@unifei.edu.br 
ABSTRACT: Regarding Special Education in the perspective of Inclusive Education, it is necessary to enhance the curriculum of undergraduate courses, especially those related to Science Teaching, with disciplines and activities that favor the knowledge related to the development of inclusive pedagogical strategies. In addition, we consider relevant that the disciplines that contemplate the inclusive aspects are based on practical rationality, to enable the future teacher subsidies to work with students with disabilities, syndrome and/or disorders. Thus, this paper aims to present results of a research conducted with a group of graduates of the courses of Physics, Chemistry, Biology and Mathematics of the Federal University of Itajubá (UNIFEI) with regard to theoretical knowledge and, in particular, practical knowledge, constructed during the formation period to work with these students in the regular context of teaching.

KEYWORDS: Inclusion. Science teaching. Teacher training.

\section{Introdução}

A pesquisa é talvez a arte de se criar dificuldades fecundas e de criá-las para os outros. Nos lugares onde havia coisas simples, faz-se aparecer problemas. (Pierre Bourdieu)

A formação inicial é uma das componentes das várias estratégias no processo da formação docente. Nóvoa (2009) argumenta que ela não é tida simplesmente como uma formação de profissionais, no entanto, também de uma profissão. Desse modo, a formação inicial é um alicerce que proporciona a construção de um conhecimento pedagógico especializado.

No entanto, para propiciar esta formação sólida, as instituições educacionais, em especial as Universidades, devem superar a concepção de que o saber escolar é um conjunto de conhecimentos eruditos. A partir dessa reflexão, consideramos que a Universidade possui um papel fundamental na formação do futuro docente, pois cabe a ela promover não apenas o conhecimento profissional, mas também o desenvolvimento dos saberes que compreendam a todos os aspectos da dimensão da profissão docente. Desse modo, o futuro profissional, além de desenvolver os saberes com relação às teorias científicas, terá a oportunidade de conviver com as suas dificuldades, limitações, além de aprender a lidar com as transformações da sociedade.

Sobre esses aspectos, tendo por base os estudos de Mizukami et.al. (2006) e Nóvoa (2009), a concepção da formação inicial varia de acordo com dois modelos, sendo eles o da racionalidade técnica ou da racionalidade prática. Segundo o modelo de racionalidade técnica, a formação profissional é um momento único e de excelência, no qual o 
profissional terá condições de apropriar o conhecimento teórico para que este possa ser aplicado futuramente.

Para Nóvoa (2009), este modelo de racionalidade técnica está enraizado nos currículos das instituições de ensino, entre elas as Universidades, que tendem a organizar as disciplinas dos cursos de formação profissional priorizando apenas as teorias e técnicas. Mizukami et al (2006) salientam que este fato ocorre por duas razões, primeiro: só é possível aprender habilidades depois de aprender o conhecimento aplicável; e segundo: as habilidades são consideradas modos de conhecimento ambíguos e secundários. Contudo, os três autores afirmam que somente mediante a aplicação desses conhecimentos é que surgem as habilidades e competências, definidas como "practicum", que são extremamente relevantes para a formação de um profissional.

É importante destacar que, estudos como os de Schön (1992), Nóvoa (1999) e Perrenoud (2002), dão conta que a falta de interesse dos educandos pelos conteúdos curriculares está relacionada à instrumentalização dos conhecimentos científicos. O professor propõe um ensino mecânico, e que não propicia uma aprendizagem significativa ao aluno. Este processo de ensino instrumental é tido como um reflexo da sua formação inicial, que além de possuir um currículo defasado, não ofereceu subsídios práticos para compreender como se configura o contexto educacional.

A nosso ver, isso torna-se ainda mais grave quando analisa-se a formação dos licenciandos para atuar na perspectiva inclusiva, pois há uma grande lacuna nos currículo dos cursos de licenciatura, em especial os relacionados ao Ensino de Ciências, onde seria necessário enriquecê-lo com atividades que favorecessem os conhecimentos relativos aos tipos de deficiência, recursos de tecnologia assistiva, materiais didáticos inclusivos, estratégias pedagógicas inclusivas e, principalmente, instigar o futuro professor a compreender que o aluno com deficiência tem condições - diante das suas limitações - de construir novos saberes e de estar em uma sala de aula regular; e evitar, assim, a manutenção ou a proliferação de práticas segregacionistas.

Para Camargo et al (2009) é fundamental que os professores estejam preparados para “[...] planejar e conduzir atividades de ensino que atendam as especificidades educacionais dos alunos com e sem deficiências [...]" (p. 1). Por isso, se torna cada vez mais urgente propiciar aos professores uma formação destinada a uma perspectiva inclusiva, para que eles possam ter segurança de atuar com esse público, até por que a 
presença dos alunos com deficiência no contexto escolar será cada vez mais frequente, já que no Brasil há quase 45,6 milhões de pessoas com alguma deficiência.

Contudo, como afirma Deimling e Caiado (2012), a formação de professores voltados para a educação especial encontra-se ainda num grande impasse. Nos cursos de licenciatura, há apenas uma recomendação ministerial que alerta para a necessidade da inclusão da área de educação especial na grade curricular do curso. Tal situação não é diferente quando se observa os cursos de licenciatura nas áreas de Física, Química, Biologia e Matemática. Sendo assim, há uma grande necessidade de repensar a organização da grade curricular visando enriquecê-las com disciplinas que valorizem a racionalidade prática que estejam relacionadas à perspectiva inclusiva. Diante disso, o presente trabalho tem como objetivo analisar a percepção de um grupo de alunos licenciandos dos cursos de Física, Química, Biologia e Matemática da Universidade Federal de Itajubá (UNIFEI) no que tange aos conhecimentos teóricos e práticos, construídos durante o período de graduação, para atuar com os estudantes com deficiência, síndrome e/ou transtornos no contexto regular de ensino.

\section{Metodologia}

A presente investigação possui características de uma pesquisa com abordagem qualitativa. Vale destacar que esse tipo de pesquisa assume diferentes formas, e para esta investigação optamos por utilizar o estudo de caso, pois por meio dele é possível analisar de forma profunda uma situação em particular. Neste trabalho optamos por analisar a percepção de um grupo de licenciandos de Ciências da UNIFEI no que concerne aos conhecimentos teóricos e práticos para atuar com os estudantes com deficiência, síndrome e/ou transtornos.

Ainda no que concerne à abordagem qualitativa, ela permite ao investigador utilizar diferentes estratégias metodológicas como, por exemplo, questionários; entrevistas; observações; análise documental, entre outras. Isso possibilita, ao pesquisador, obter diversas informações sobre o objeto investigado.

É importante compreender que essa investigação é considerada um estudo de caso. Para esse tipo de pesquisa a entrevista é considerada um dos instrumentos mais importantes, pois permite obter a informação de forma imediata (LUDKE \& ANDRÉ, 1986), e ela “[...] favorece não só a descrição dos fenômenos sociais, mas também sua 
explicação e a compreensão de sua totalidade [...]". Cabe compreender que existem três tipos de entrevista: a estruturada, onde as perguntas são previamente definidas, a não estruturada, na qual o pesquisador tem a oportunidade de introduzir um tema e o entrevistado tem total liberdade para dialogar sobre o tema proposto, e a semi-estruturada, que acontece a partir de uma estrutura básica, mas que não é aplicada rigidamente (LUDKE; ANDRE, 1986).

Nessa investigação foi utilizada a entrevista estruturada, com 17 questões abertas que, posteriormente, foram enviadas por email a um grupo de alunos dos cursos de Licenciatura em Física, Química, Biologia e Matemática da UNIFEI. Para garantir o sigilo ético sobre a identidade de cada sujeito, nos resultados utilizamos identificações - como A1 - para designá-los. A partir dos dados coletados realizamos uma Análise Textual Discursiva, que teve início com uma unitarização que permitiu separar os textos em unidades de significado. Posteriormente, foi realizada a análise dos dados de modo a articulá-los por significados semelhantes em um processo de categorização (MORAES \& GALIAZZI, 2006). Para tanto, elaboramos 02 (duas) categorias de análise: a) conhecimentos práticos na licenciatura - tinha-se o intuito de verificar a percepção dos licenciandos no que concerne à formação prática para atuar no contexto inclusivo; $b$ ) $a$ prática pedagógica inclusiva para ensinar os conteúdos de Ciências - analisar se os licenciandos sentiam-se preparados para ensinar os conteúdos específicos de suas áreas de atuação aos alunos com deficiência, síndrome e/ou transtornos.

\section{Resultados e Discussão}

A partir da Análise Textual Discursiva os dados foram analisados, sistematizados e categorizados. Sendo assim, a seguir, apresenta-se a discussão dos dados.

\section{a) Conhecimentos práticos na licenciatura}

A prática pedagógica é um dos elementos essenciais para possibilitar aos licenciandos subsídios para atuar com os alunos com deficiência, síndrome e/ou transtornos. Desse modo, durante a entrevista, eles destacaram que essa prática poderia ser vivenciada em disciplinas como, por exemplo, estágio. Os licenciandos ainda ponderaram sobre a possibilidade da universidade desenvolver projetos em escolas que tenham alunos com deficiência matriculados. Essa ação viabilizaria a presença dos graduandos nesse 
contexto, assim como um contato mais estreito com esses alunos. Isso fica claro nos argumentos apresentados a seguir:

Acredito que a bagagem de conhecimentos que recebemos na faculdade ainda é muito baixa e a falta de prática nos prejudica ainda mais. (A6)

Em minha opinião para potencializar minha aprendizagem sobre a inclusão de pessoas com deficiência, síndrome elou transtorno os conteúdos das disciplinas deveriam ser trabalhados de forma a articular a teoria com a prática, aproximando os conceitos teóricos da prática docente por meio de experiências, tais como: parcerias e realização de projetos em escolas que possuem alunos Público Alvo da Educação Especial. (A1)

Acredito que a abordagem de forma mais prática ajudaria a potencializar o aprendizado. Acredito também que as disciplinas inclusivas deveriam ser trabalhadas no estágio. No meu curso nós acompanhamos ensino médio durante 4 semestres. Poderia ser utilizado pelo menos um desses semestres para realizarmos um trabalho em uma escola que nos proporcione essa experiencia. (A3)

Desde o começo do período, incluído no estágio supervisionado o contato e desenvolvimento de projetos voltados para esse público, além de poder conhecer as instituições próximas que trabalham com essas pessoas. (A5)

Dialogando com essa ideia, Perrenoud (2002) salienta que as universidades deveriam estabelecer parcerias mais amplas e equitativas com as instituições escolares e com os professores tutores que acolhem esses estagiários. Sob este enfoque, Camargo e Nardi (2008), investigaram a estrutura curricular dos cursos de licenciatura em Física e por meio da análise dos dados verificaram que para uma parcela expressiva de alunos existe a urgência de aprofundar o conhecimento relacionado às disciplinas de natureza pedagógica. Os alunos entrevistados argumentaram que essas disciplinas poderiam ser sugeridas no primeiro semestre do curso, e assim o contato seria no seu decorrer. A pesquisa também mostrou que alunos do último ano da graduação não se sentiam seguros para iniciar a carreira docente, comprovando que a formação inicial possui aspectos falhos e obsoletos.

Os dados também revelaram que existe uma preocupação, por parte dos licenciados, em aprimorar o conhecimento sobre as práticas pedagógicas; e que os cursos de formação lhes ofereçam subsídios para atuar como profissionais qualificados. Os alunos A2 e A9 demonstraram preocupação em relação às disciplinas relacionadas às Práticas de Ensino. Os alunos revelam que essas disciplinas abordam apenas os conteúdos específicos 
das Ciências, mas não possibilitam aos licenciandos refletir e implementar estratégias que contemplem os aspectos inclusivos, como verifica-se nas falas abaixo:

Eu queria alertar para a disciplina de Prática de ensino que deve abordar esses temas e não só ficar nas histórias da ciência, analisando livros didáticos [...]. (A2)

[...] esse semestre cursei prática de ensino II e em nenhum momento foi abordado o tema. Os assuntos discutidos foram irrelevantes para mim. Acho que a disciplina deve ser reformulada. (A9)

Para A5 é fundamental que as disciplinas voltadas para a temática inclusiva convidem os alunos com deficiência, síndrome e/ou transtornos para dialogar, uma vez que essa ação oportuniza um momento de compartilhamento e troca de conhecimentos, como se observa no relato a seguir:

Acho que nas disciplinas que envolvem essa temática deveria haver o contato com esses alunos com deficiência, vivenciando o momento de troca de saberes, para que a teoria faça ligação com a prática. (A5)

A nosso ver isso, torna-se interessante, em especial, quando a instituição possui um número reduzido, ou até mesmo inexistente, de graduandos com deficiência matriculados. Todavia, cabe destacar que esse cenário tende a mudar nas instituições federais com a Lei n. 13.409/2016, a qual estabelece como direito a reserva de vagas para pessoas com deficiência, síndromes, transtornos globais do desenvolvimento e altas habilidades e superdotação.

\section{b) A prática pedagógica inclusiva para ensinar os conteúdos de Ciências}

Com a entrevista também se tinha o objetivo de verificar se os licenciandos sentiam-se preparados para ministrar os conteúdos específicos de Ciências. Desse modo, a partir dos relatos abaixo se observa a importância de aprimorar a grade curricular dos cursos de licenciatura em Ciências, em especial os da UNIFEI. Tanto A4 como A10 revelam que não possuem conhecimentos para trabalhar os saberes específicos de suas áreas de forma inclusiva.

Acredito que a bagagem de conhecimentos que recebemos na faculdade ainda é muito baixa e a falta de prática nos prejudica ainda mais. Nesse caso, não, não possuo conhecimento suficiente. (A4)

Não. Neste instante não, porque faltam algumas informações $e$ experiência que ainda não tenho [...]. (A10) 
Já A7 destaca que, se determinados alunos que não apresentam deficiência, síndrome e/ou transtorno já consideram os conteúdos curriculares de Química complexos, o desafio será ainda maior com os estudantes que fazem parte do universo da Educação Inclusiva. Para A11 e A12 haverá dificuldades para abordar os conteúdos curriculares de matemática como, por exemplo, trigonometria, com os alunos cegos. Diante disso, observa-se que o processo de ensino e aprendizagem exigirá ainda mais desse docente, uma vez que ele deverá buscar meios para que o conhecimento científico seja "acessível a todas às pessoas, englobando as diferentes necessidades de aprendizagem de cada sujeito" (BENITE et.al, 2015, p.90), evitando, assim, que o aluno com deficiência fique à margem da sala de aula.

A química já é bem complexa para alunos não cegos, realmente, são muitos os conteúdos que eu encontraria dificuldade, mas não deixaria de me esforçar para desenvolver uma maneira de incluir esse meu aluno com cegueira. (A7)

Acredito que um dos conteúdos relativos à minha área de formação acadêmica que seria complexo para ensinar um aluno com cegueira é a trigonometria, posto que este conteúdo demanda um nível de abstração muito elevado e acredito que não se tenha muitos recursos concretos para trabalhar com esse conteúdo, eu pelo menos desconheço. (A11)

No caso de um aluno com cegueira dos dois olhos, acho que as fórmulas seriam mais complexas, pois, no alfabeto Braille ainda não há símbolos para expressar tudo o que precisamos em Matemática. (A12)

Do mesmo modo, P8 também salientou que é desafiador ensinar os saberes específicos da área de matemática para os alunos que fazem parte do público-alvo da Educação Inclusiva.

É sempre desafiador ministrar conteúdos relativos ao ensino de ciências e em particular ao ensino de matemática para alunos com deficiência, síndrome elou transtorno, [...] a participação nos projetos vinculados com o grupo de pesquisa NEFTI tem me proporcionado vivenciar essa prática e colabora para minha preparação para lidar com esse desafio. Por esse motivo considero que estou em me preparando para lecionar a esses alunos. (A8)

Por outro lado, na fala de P8 observa-se que, diferente dos demais licenciandos, ele participa de um grupo de pesquisa na universidade que possui atividades práticas que envolvem esses sujeitos. Diante disso, teve a oportunidade de aprender a criar e implementar os conteúdos curriculares de forma inclusiva. 


\section{Considerações finais}

Com base nos dados, tem-se a necessidade de investir esforços para alterar a grade curricular dos cursos de licenciatura de Ciências, em especial os da UNIFEI. Destaca-se que é fundamental enriquecê-lo com disciplinas práticas que favoreçam: a troca de conhecimento; a reflexão; a construção de experiências interdisciplinares; atividades relacionadas às diferentes práticas de ensino; e a compreensão do conceito de avaliação no que tange à perspectiva inclusiva, contemplando os conteúdos e saberes específicos das Ciências.

É importante também compreender a relevância dos currículos dos cursos de licenciatura serem concebidos e estruturados contemplando o modelo da racionalidade prática, pois a prática assume um papel primordial no currículo dos cursos de licenciatura, configurando-se como um momento de desenvolvimento de capacidades, competências e habilidades, implicando na construção de novo conhecimento perante a ação. Neste processo, não há uma relação com o conhecimento científico, mas sim um diálogo entre este novo saber e uma situação real, que abre um espaço para uma nova aprendizagem.

Diante de todo esse cenário, alertamos para a urgência de repensar as disciplinas práticas dos cursos relacionados ao ensino das Ciências, pois a nosso ver as práticas segregacionistas não podem mais fazer parte do contexto educacional. E, além disso, a universidade tem a responsabilidade de formar profissionais capacitados que, ao adentrar no universo escolar, possam aproximar os alunos com deficiência, síndrome e/ou transtornos dos saberes científicos.

\section{REFERÊNCIAS}

BENITE, A. M. C.; BENITE, C. R. M; VILELA-RIBEIRO, E. V. Educação Inclusiva, ensino de Ciências e linguagem científica: possíveis relações. Revista Educação Especial, v. 28, n. 51, jan./abr. 2015.

CAMARGO, S.; NARDI, R. A Elaboração de uma estrutura curricular e a formação de professores de Física:as intenções legais, os processos de operacionalização, os discursos dos formadores e suas práticas docentes. In: NARDI, R.; BASTOS, F. (org.). Formação de professores e práticas pedagógicas no ensino de ciências: contribuições da pesquisa na área. São Paulo: Escrituras Editora, 2008.

CAMARGO, Eder Pires de.; et al. Ensino de Física e deficiência visual: diretrizes para a implantação de uma nova linha de pesquisa. In: XVIII SIMPÓSIO NACIONAL DE ENSINO DE FÍSICA, 2009, Vitória. Disponível em: 
<http://www.sbf1.sbfisica.org.br/eventos/snef/xviii/sys/resumos/T0609-2.pdf>. Acesso em: 07 jun. 2018.

DEIMLING, N. N. M.; CAIADO, K. R. M. Formação de professores para a educação inclusiva nos cursos de pedagogia das universidades públicas paulistas. Rev.Teoria e prática da educação, v. 15, n. 3, p. 51-64, setembro/dezembro., 2012.

LÜDKE, M.; ANDRÉ, M. E. D. A. Pesquisa em Educação: abordagens qualitativas, temas básicos de educação e ensino. Editora Pedagógica e Universitária LTDA, 1986.

MIZUKAMI, M. G. N. Aprendizagem da docência: conhecimento específico, contextos e práticas pedagógicas. In: NACARATO, A. M.; PAIVA, M. A. V. (Org.). A formação do professor que ensina Matemática: perspectivas e pesquisas. Belo Horizonte: Autêntica, 2006. p. 213-231

MORAES, R.; GALIAZZI, M. C. Análise textual discursiva: processo reconstrutivo de múltiplas faces. Ciência \& Educação, Bauru, v. 12, n. 1, p. 117-128, 2006.

NÓVOA, A. Professores: Imagens do Futuro Presente. Educa Lisboa, 2009.

PERRENOUD, P.; et al. As Competências para ensinar no século XXI: a formação dos professores e o desafio da avaliação. Tradução: Claudia Schilling e Fátima Murad. Porto Alegre: Artmed, 2002.

\section{Como referenciar este artigo}

RODRIGUES, Paloma Alinne Alves. A formação de professores de Ciências para uma prática pedagógica inclusiva. Revista Ibero-Americana de Estudos em Educação, Araraquara, v. 13. n. esp. 2, p. 1149-1458, set., 2018. ISSN: 1982-5587. DOI: 10.21723/riaee.v13.nesp2.set2018.11654

Submetido em: 15/02/2018

Aprovado em: 10/04/2018 